\title{
Characterization and Trypanocidal Activity of a Novel Pyranaphthoquinone
}

\author{
Elen Diana Dantas ${ }^{1}$, Fabia Julliana Jorge de Souza ${ }^{1}$, William Nascimento Litaiff Nogueira ${ }^{1}$, \\ Cláudia Cândida Silva ${ }^{2}$, Pedro Henrique Antunes de Azevedo ${ }^{1}$, Cícero Flávio Soares Aragão ${ }^{1}$ (D), \\ Patricia Danielle Oliveira de Almeida ${ }^{3}$, Mariana Filomena do Carmo Cardoso ${ }^{4}$, \\ Fernando de Carvalho da Silva ${ }^{4}$ (D), Eduardo Pereira de Azevedo ${ }^{5}$, Euzébio Guimarães Barbosa ${ }^{1}$, \\ Emerson Silva Lima ${ }^{3}$ (D), Vitor Francisco Ferreira ${ }^{4}$ and Ádley Antonini Neves de Lima ${ }^{1, *}$ \\ 1 Pharmacy Department, Health Sciences Center, Universidade Federal do Rio Grande do Norte (UFRN), \\ Natal RN 59012-570, Brazil; elendiana88@gmail.com (E.D.D.); fabiajulliana@gmail.com (F.J.J.d.S.); \\ will_litaiff@hotmail.com (W.N.L.N.); pedrohenriqueantunesdeazevedo@hotmail.com (P.H.A.d.A.); \\ cicero.aragao@yahoo.com.br (C.F.S.A.); euzebiogb@gmail.com (E.G.B.) \\ 2 Crowfoot Group of X-ray Techniques, Universidade Estadual do Amazonas (UEA), Manaus AM 69065-020, \\ Brazil; claudiacsbr@gmail.com \\ 3 Biological Activities Laboratory, Universidade Federal do Amazonas (UFAM), Pharmaceutical Sciences, \\ Manaus AM 69080-900, Brazil; patt_danielle@hotmail.com (P.D.O.d.A.); eslima@ufam.edu.br (E.S.L.) \\ 4 Laboratory of Synthesis of Bioactive Molecules, Organic Chemistry Department, Universidade Federal \\ Fluminense (UFF), Niterói RJ 24020-141, Brazil; marianafcc83@hotmail.com (M.F.d.C.C.); \\ gqofernando@vm.uff.br (F.d.C.d.S.); cegvito@vm.uff.br (V.F.F.) \\ 5 Graduate Program in Biotechnology, Laureate International Universities-Universidade Potiguar (UnP), \\ Natal RN 59056-000, Brazil; azevedoep@hotmail.com \\ * Correspondence: adleyantonini@yahoo.com.br; Tel.: +55-849-992-88864
}

Received: 12 September 2017; Accepted: 28 September 2017; Published: 30 September 2017

\begin{abstract}
Chagas disease is an endemic parasitic infection that occurs in 21 Latin American countries. New therapies for this disease are urgently needed, as the only two drugs available (nifurtimox and benznidazol) have high toxicity and variable efficacy in the disease's chronic phase. Recently, a new chemical entity (NCE) named Pyranaphthoquinone (IVS320) was synthesized from lawsone. We report herein, a detailed study of the physicochemical properties and in vitro trypanocidal activity of IVS320. A series of assays were performed for characterization, where thermal, diffractometric, and morphological analysis were performed. In addition, the solubility, permeability, and hygroscopicity of IVS320 were determined. The results show that its poor solubility and low permeability may be due to its high degree of crystallinity $(99.19 \%)$, which might require the use of proper techniques to increase the IVS320's aqueous solubility and permeability. The trypanocidal activity study demonstrated that IVS320 is more potent than the reference drug benznidazole, with IC50/24 h of $1.49 \pm 0.1 \mu \mathrm{M}$, which indicates that IVS320 has potential as a new drug candidate for the treatment of Chagas disease.
\end{abstract}

Keywords: physicochemical characterization; IVS320; quinone; T. cruzi; Chagas disease; pyranaphthoquinone

\section{Introduction}

Chagas disease, a parasite infection caused by the protozoan Trypanosoma cruzi (T. cruzi), is considered a health problem in Latin America due to inappropriate therapy and lack of an effective vaccine [1]. It is estimated that this infection affects about 8-9 million people in Latin America, causing about 10,000 deaths each year [2]. In the last decade, however, the migration of infected individuals 
with T. cruzi from endemic countries to non-endemic countries in North America, Europe, Asia, and Oceania has caused the spread of this disease around the world [3].

In the 1970s, nifurtimox and benznidazole appeared as the first effective drugs for the treatment of Chagas' disease. The use of these drugs for long periods has been associated with several adverse effects [4]. In fact, nifurtinox has been discontinued due to serious side effects. Currently, benzinidazole (N-benzyl-2-nitro-1-imidazole acetamide) is the only drug available for the treatment of Chagas' disease [5]. However, its low efficacy in the chronic phase of the disease, the high discontinuity of treatment due to its many side effects, and its low solubility have limited its clinical use [6].

Quinones represent an important class of biologically active molecules [7]. Naphthoquinones are a type of quinone that have a chemical structure based on the naphthalene ring [8]. The naphthoquinones (found in bacteria and fungi) have been extensively studied in recent years, not only because of their role in vital biochemical processes, but also due to their wide range of pharmacological properties such as antineoplastic [9-11], antimicrobial [11,12], insecticidal [13], antimalarial [14], anti-inflammatory [15] leishmanicidal [16,17], trypanocide [16], and antifungal [18].

Recently, a pyranaphthoquinone (IVS320-Figure 1) was synthesized [19] and it has shown activity against Candida albicans, dermatophytes and Cryptococcus spp. [20]. However, IVS320's trypanocidal activity is still unknown.

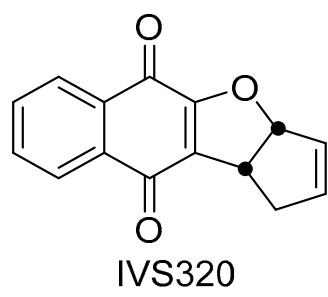

Figure 1. Chemical structure of IVS320 (3a,10b-dihydro-1H-cyclopenta[b]naphtho[2,3- $d]$ furan-5,10-dione).

In this study, physicochemical characterization of IVS320 through X-ray Diffraction (XRD), Fourier-Transform Infrared spectroscopy (FTIR), X-ray Fluorescence by Dispersion of Energy (XRFDE), and thermal analysis such as Differential Scanning Calorimetry (DSC), Thermogravimetry (TG), and Differential Thermal Analysis (DTA) were performed. In addition, IVS320's hygroscopicity, solubility, and partition coefficient were determined. Finally, the trypanocidal activity of IVS320 against tissue culture trypomastigotes forms of T. cruzi was investigated.

\section{Results and Discussion}

\subsection{Thermal Analysis}

The DSC curve for IVS320 (Figure 2) confirmed the three events characteristic of the thermal behavior of this material, where a sharp endothermic event is observed between 191 and $196{ }^{\circ} \mathrm{C}$ indicating IVS320 melting $\left(T_{\text {peak }} 194^{\circ} \mathrm{C}, \Delta H-65.33 \mathrm{~J} \cdot \mathrm{g}^{-1}\right)$. A second event is observed as an exothermic between 199 and $211^{\circ} \mathrm{C}\left(T_{\text {peak }} 205^{\circ} \mathrm{C}\right)$, followed by another exothermic event between 256 and $264^{\circ} \mathrm{C}$ ( $T_{\text {peak }} 277^{\circ} \mathrm{C}$ ), which seems to be attributed to the recrystallization of IVS320, indicating a possible change to another crystalline form.

By definition, polymorph is a compound that has at least two crystalline arrangements and although they have the same chemical composition, polymorphs usually exhibit different physicochemical properties. Therefore, aspects such as solubility, toxicity, and stability tend to change between the different crystalline forms [21]. Considering this information, it would be worthwhile investigating the different crystal forms of IVS320 by thermomicroscopy in a subsequent study.

When the thermal events of IVS320 are compared with other 2-Hydroxy-1,4-naphthoquinone ( $\beta$-lapachone) derivatives with chemical structures similar to IVS320, some differences in the 
thermal events are observed. For instance, the thermal analysis of $\beta$-lapachone does not show any recrystallization event. Instead, two events are observed, where the first one is due to $\beta$-lapachone's melting $\left(\mathrm{T}_{\text {peak }} 156, \mathrm{~T}_{\text {onset }} 156\right.$ and $\left.\Delta H 122 \mathrm{~J} \cdot \mathrm{g}^{-1}\right)$ and the second corresponds to its decomposition $\left(256.3^{\circ} \mathrm{C}\right.$ and $\left.\Delta \mathrm{H} 69.4 \mathrm{~J} \cdot \mathrm{g}^{-1}\right)$ [22].

The TG/DTG curves (Figure 2) show that IVS320 is thermally stable up to $150{ }^{\circ} \mathrm{C}$, where three stages of mass loss can be observed. The first stage of mass loss $(-4 \%$ decrease) occurred in the temperature range of $150-262{ }^{\circ} \mathrm{C}$ (both in air and in $\mathrm{N}_{2}$ atmosphere), whereas the second stage $(-26 \%$ decrease) occurred in the temperature range of $262-532{ }^{\circ} \mathrm{C}$ (air) $\left(-6 \%\right.$ decrease) and $262-315{ }^{\circ} \mathrm{C}\left(\mathrm{N}_{2}\right.$ atmosphere). The third stage of mass loss $(-69 \%$ decrease) occurred in the temperature range of 532-662 ${ }^{\circ} \mathrm{C}$ (air, $-22 \%$ decrease) and 315 to $900{ }^{\circ} \mathrm{C}\left(\mathrm{N}_{2}\right)$. The DTG curves differ only in the fourth event in air atmosphere ( $\mathrm{T}_{\text {peak }}$ DTG $595^{\circ} \mathrm{C}$ ), which corresponds to the mass loss observed in the TG.

The DTA curve (Figure 2) showed the first endothermic event between $194-203{ }^{\circ} \mathrm{C}$ indicating melting $\left(T_{\text {peak }} 197^{\circ} \mathrm{C}\right.$, Heat $\left.-62 \mathrm{~J} \cdot \mathrm{g}^{-1}\right)$, the second exothermic event between $209-218^{\circ} \mathrm{C}$ indicating melting $\left(T_{\text {peak }} 217^{\circ} \mathrm{C}\right.$, Heat $\left.518 \mathrm{~J} \cdot \mathrm{g}^{-1}\right)$, the third exothermic event between $262-416^{\circ} \mathrm{C}$ indicating melting $\left(T_{\text {peak }} 288{ }^{\circ} \mathrm{C}\right.$, Heat $\left.229 \mathrm{~J} \cdot \mathrm{g}^{-1}\right)$, and the fourth one exothermic between $499-619{ }^{\circ} \mathrm{C}\left(T_{\text {peak }}\right.$ $580^{\circ} \mathrm{C}$, Heat $\left.7.44 \mathrm{~kJ} \cdot \mathrm{g}^{-1}\right)$.

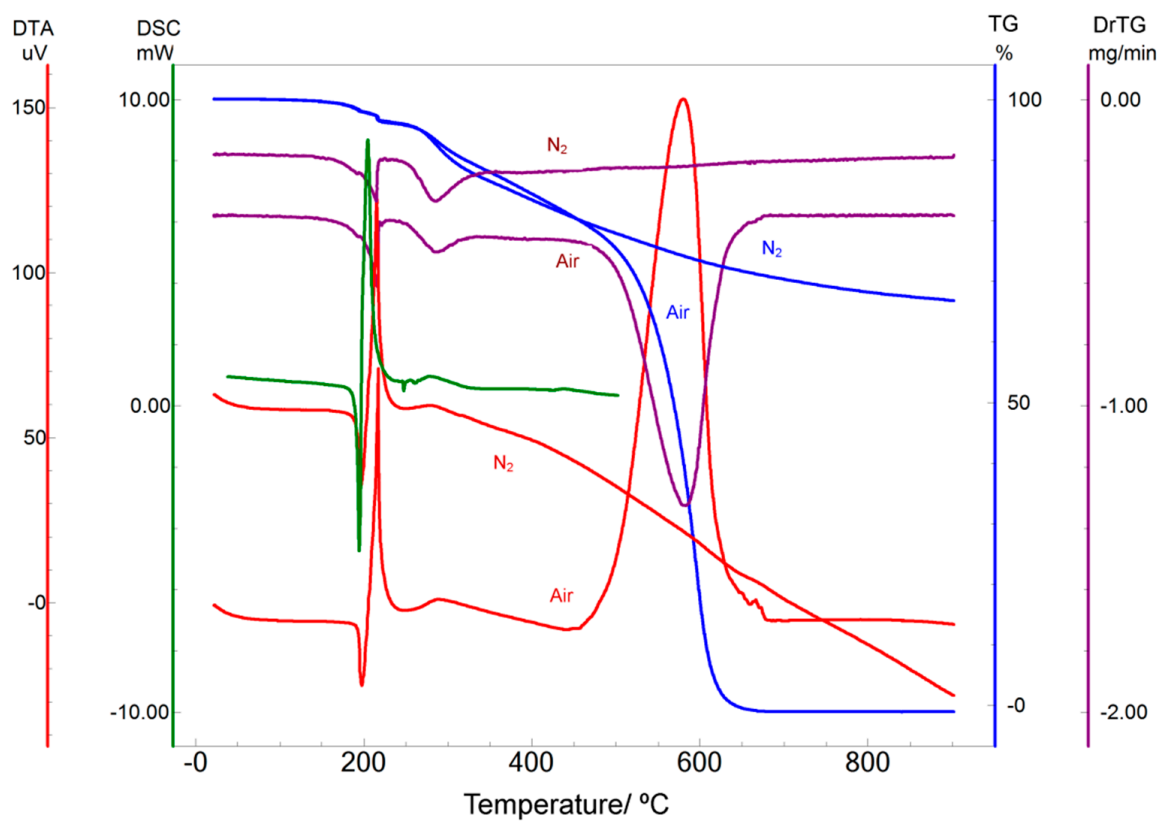

Figure 2. Differential scanning calorimetry (DSC), thermogravimetry TG/DrTG and differential thermal analysis (DTA) curves for IVS320 obtained at a heating rate of $10^{\circ} \mathrm{C} \cdot \mathrm{min}^{-1}$ in a dynamic air and nitrogen atmospheres $\left(50 \mathrm{~mL} \cdot \mathrm{min}^{-1}\right)$.

\subsection{X-ray Fluorescence}

X-ray fluorescence analysis shows the presence of some elements in the IVS320 sample, especially sodium, which is present at a concentration of $22 \%$ (Table 1 ). This relatively high amount of sodium might have been originated from the route of synthesis and isolation of this material, as well as from the reagents used in the synthesis process. In fact, anhydrous sodium sulfate was generated as solvent waste during IVS320 synthesis, which might explain the high sodium content.

Other elements such as magnesium, aluminum, sulfur, and copper are also present, although in fairly low amounts (below \%). Just like sodium, these elements are chemical reagents used in the synthesis of IVS320. These results demonstrate that other than the original IVS320 molecule, there are additional chemical elements in the sample used in this study. 
X-ray fluorescence has been an important analytical tool for assessing the purity of drugs and excipients, being able to detect even small traces of contaminants, as demonstrated in this study.

Table 1. X-ray fluorescence analysis of IVS320.

\begin{tabular}{cc}
\hline Chemical Element & Concentration $\%(w / w)$ \\
\hline $\mathbf{N a}$ & 22.13 \\
$\mathbf{M g}$ & 0.579 \\
$\mathrm{Al}$ & 0.615 \\
$\mathrm{~S}$ & 0.03 \\
$\mathrm{Cu}$ & 0.01 \\
\hline
\end{tabular}

\subsection{X-ray Diffraction}

The X-ray diffractogram of IVS320 (Figure 3a) shows a series of high-intensity diffraction peaks at $10.30,11.10,14.34,24.38$ and $28.77^{\circ}(2 \theta)$ in addition to several others secondary low-intensity peaks, indicating a crystalline structure.

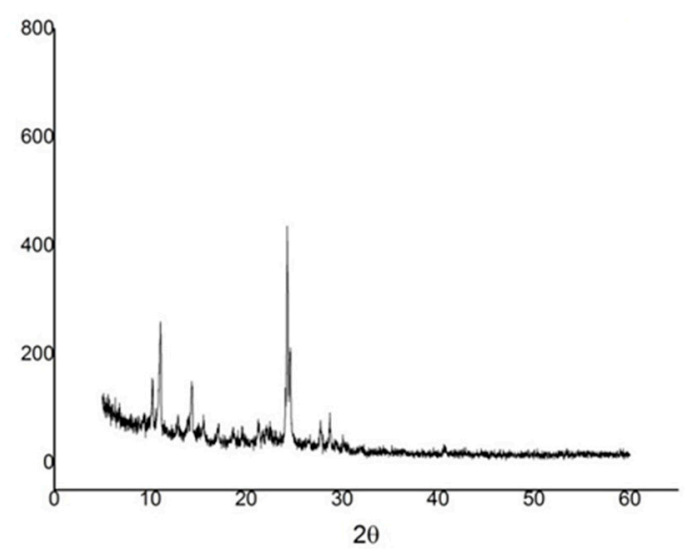

(a)

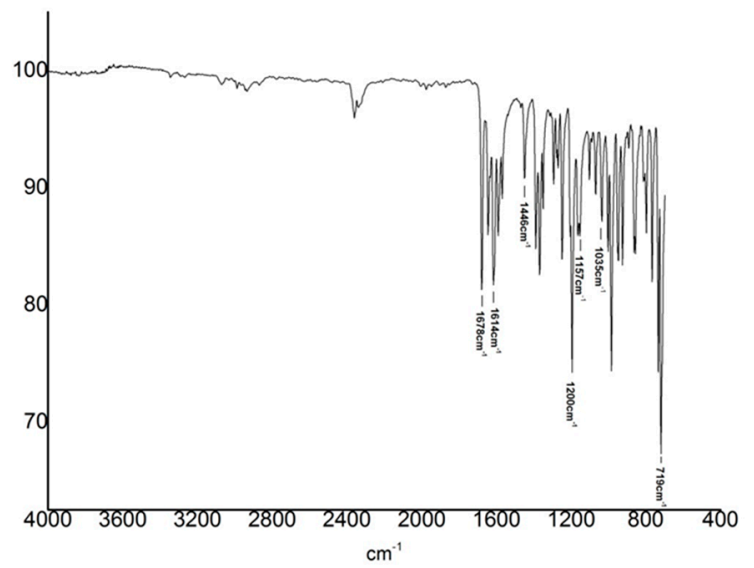

(b)

Figure 3. X-ray diffraction pattern (a) and Fourier-transform infrared (FT-IR) spectrum (b) of IVS320.

Additionally, its crystalline nature was confirmed with the result of the percentage of crystallinity (99.19\%). Thus, the X-ray diffraction results indicate that the relatively high crystalline pattern of IVS320 might impair its solubility as highly crystalline compounds are usually poorly soluble in water [23].

\subsection{Fourier Transform Infrared (FT-IR)}

The FT-IR spectrum for IVS320 (Figure 3b) shows characteristic bands attributed to symmetrical carbonyl groups of naphthalene ring (stretching vibration at $1678 \mathrm{~cm}^{-1}$ ). Other bands were attributed to the $C=C$ stretching vibration of cyclopentene $\left(1614 \mathrm{~cm}^{-1}\right)$ and the ones due to the benzene ring (1,2-disubstituted) at $1157 \mathrm{~cm}^{-1}, 1035 \mathrm{~cm}^{-1}$ and $719 \mathrm{~cm}^{-1}$. In addition, a strong band is observed at $1200 \mathrm{~cm}^{-1}$ due to the asymmetrical stretching of $\mathrm{C}-\mathrm{O}-\mathrm{C}$.

\subsection{Scanning Electron Microscopy (SEM)}

SEM has been extensively used as a qualitative method to study the morphological aspects of solids. Figure 4 shows the micrograph of IVS320, where irregularly shaped crystals with various sizes and a predominance of a pyramidal form are observed. Such morphological findings are in accordance with those of naphthoquinone derivatives of 2-Hydroxy-1,4-naphthoquinone (lawsone), as previously 
reported [22]. The crystalline nature of IVS320 shown in the SEM micrograph corroborates the results of the X-ray diffraction analysis.

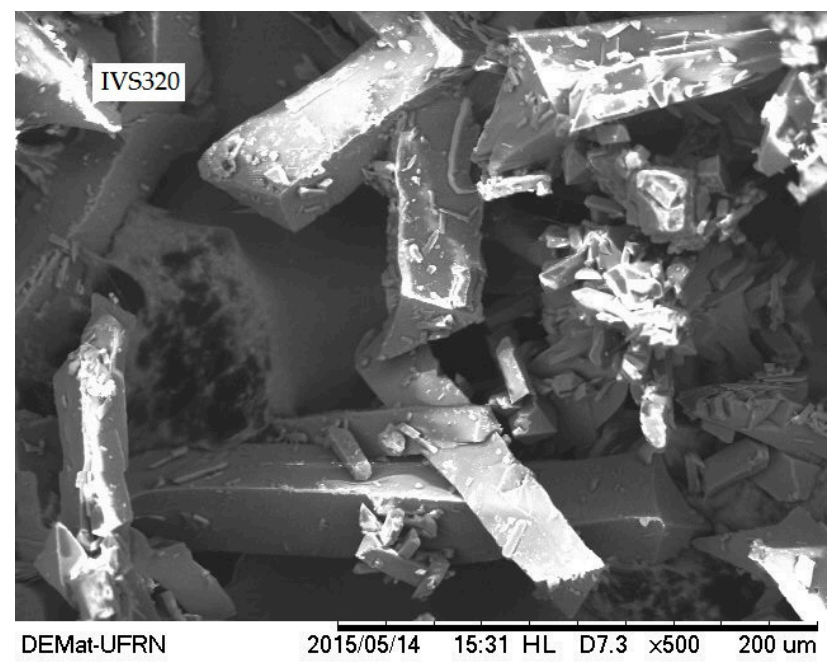

Figure 4. Scanning electron microscopy (SEM) micrograph of IVS320 at magnification of 500×.

\subsection{Hygroscopicity}

Hygroscopicity can be defined as the tendency of a material to absorb moisture from the surrounding environment [24]. The compounds used for pharmaceutical applications are exposed to different humidity levels during the development stages such as synthesis, grinding, spray or freeze drying, wet milling, granulation, storage, and analysis [25].

Adsorption of water molecules may affect the stability, flow, dissolution, compressibility, and compatibility of powder mixtures used to manufacture pharmaceutical solid dosage forms [26,27]. Therefore, the interaction between the sample and water is of great interest in the preformulation studies of new drug candidates.

In this study, IVS320 was classified as a non-hygroscopic material according to the criteria depicted on Table 2 [28], as it shows a very low water adsorption capacity $(\mathrm{H} \%<0.01)$ regardless of the relative humidity condition (88.8\% and 70.4\%). In addition, the $\mathrm{H} \%$ did not change from 3 to $72 \mathrm{~h}$ and therefore, it seems reasonable to infer that the $\mathrm{H} \%$ reached its peak. These results indicate that the physical and physicochemical properties of IVS320 will not change even at high levels of humidity during storage and manufacturing.

Table 2. Hygroscopicity classification [28].

\begin{tabular}{cl}
\hline Classification & \multicolumn{1}{c}{ Criteria } \\
\hline Non-hygroscopic & $\begin{array}{l}\text { No moisture increase at humidity levels below } 90 \% \text {. Less than } 20 \%(w / w) \text { increase in moisture } \\
\text { content at humidity levels above } 90 \% \text { after 1 week of storage. }\end{array}$ \\
\hline Slightly hygroscopic & $\begin{array}{l}\text { No moisture increase at humidity levels below } 80 \% \text {. Less than } 40 \%(w / w) \text { increase in moisture } \\
\text { content at humidity levels above } 80 \% \text { after 1 week of storage. }\end{array}$ \\
\hline Moderately hygroscopic & $\begin{array}{l}\text { Moisture content does not increase }>5 \%(w / w) \text { at humidity levels below } 60 \% \text {. Less than } 50 \% \\
(w / w) \text { increase in moisture content at humidity levels above } 80 \% \text { after 1 week of storage. }\end{array}$ \\
\hline Very hygroscopic & $\begin{array}{l}\text { Moisture content increases at humidity levels as low as } 40-50 \% \text {. Greater than } 20 \%(w / w) \\
\text { increase in moisture content at humidity levels above } 90 \% \text { after week of storage. }\end{array}$ \\
\hline
\end{tabular}

\subsection{Partition Coefficient/Lipophilicity}

The permeation of any drug through biological membranes depends on its lipophilicity and therefore the drug's absorption can be correlated with its partition coefficient [24].

The experimental lipophilicity (LogP) for IVS320 in 1-octanol/water system was 2.08 (standard deviation of 0.046 , as shown in Table 3), which classifies it as a low permeability drug. 
Table 3. Results of LogP from the triplicate experiments.

\begin{tabular}{cc}
\hline Data & $\log P^{*}$ \\
\hline $\mathbf{1}$ & 2.04 \\
$\mathbf{2}$ & 2.13 \\
$\mathbf{3}$ & 2.07 \\
\hline * Standard deviation was calculated as 0.046.
\end{tabular}

The computational LogP, which was calculated using the Marvin Sketch software, was 1.64. The proximity between the experimental and computational values seems to indicate the reliability of these methods.

Computational $\log P$ for other naphthoquinone derivatives show lower values [29], which seems to indicate a decreased lipophilicity in comparison to IVS320.

\subsection{Solubility}

Solubility is a key factor that must be determined for any new chemical entity with potential as a drug candidate. This is because the drug's dissolution rate and hence its bioavailability is a function of the solubility of the molecule [24].

In this study, qualitative analysis shows that IVS320 is insoluble in water and in most organic solvents tested. However, it is soluble in acetic acid, acetic anhydride, and acetone, where these last two are the most used solvents for IVS320 analytical and extraction purposes.

In order to predict the solubility of IVS320, a calibration curve was obtained using solutions at six different concentrations $(10,15,20,25,30$ and $35 \mu \mathrm{g} / \mathrm{mL})$, where the equation $\mathrm{y}=0.49 \mathrm{x}+0.022$, with $R^{2}=0.994$ was then obtained. By using this equation, the quantitative solubility in water was calculated as $0.0121 \mu \mathrm{g} / \mathrm{mL}$ (standard deviation of 0.0013 , as shown in Table 4), which classifies this drug as poorly soluble or insoluble in water, a result that confirms the qualitative solubility data.

Table 4. Results of solubility of IVS320 from the triplicate experiments.

\begin{tabular}{cc}
\hline Data & Solubility $(\mu \mathrm{g} / \mathrm{mL}) *$ \\
\hline $\mathbf{1}$ & 0.0108 \\
$\mathbf{2}$ & 0.0134 \\
$\mathbf{3}$ & 0.0122 \\
\hline
\end{tabular}

* Standard deviation was calculated as 0.0013 .

Such poor aqueous solubility must be due to IVS320's low polarity and high degree of crystallinity, as evidenced by the X-ray diffraction analysis (Figure 3a). In fact, the low water solubility of this drug is not an uncommon feature, as an estimated $40 \%$ of new chemical entities are lipophilic and therefore are poorly soluble in water [30].

\section{Trypanocidal Activity}

The trypanocidal activity of IVS320 was evaluated against tissue culture trypomastigotes forms of $T$. cruzi (Y strain) through the determination of $\mathrm{IC}_{50}$. IVS320 showed a potent anti-T. cruzi activity, being able to efficiently lyse the trypomastigotes forms. The IC Fo $_{50}$ IVS320 was $1.49 \pm 0.1 \mu \mathrm{M}$ against $11.4 \pm 1.4 \mu \mathrm{M}$ of the reference drug benznidazole (Figure 5). 


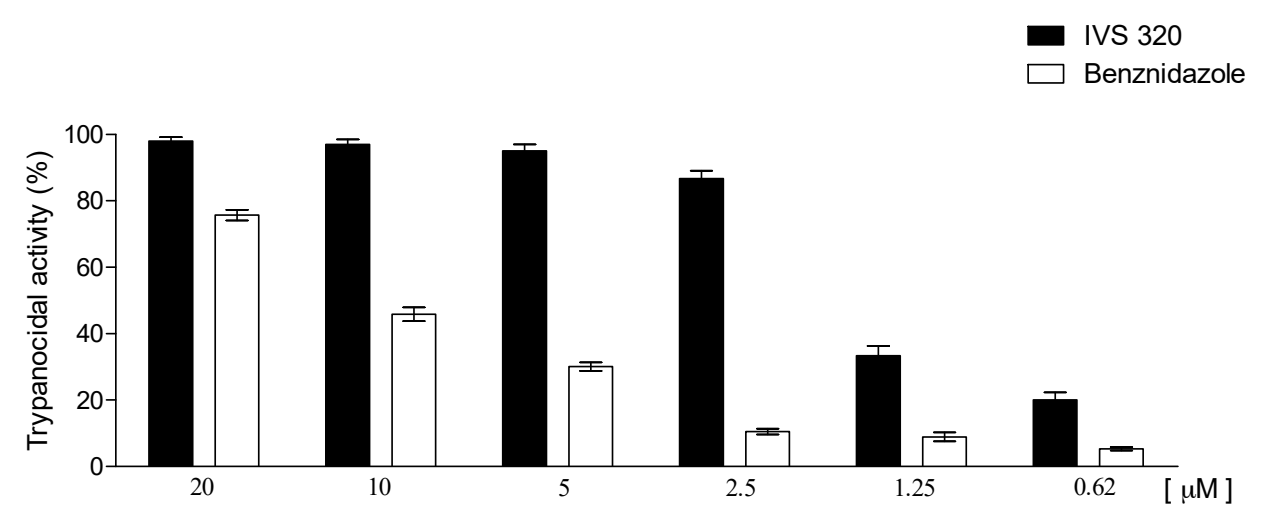

Figure 5. Effect of IVS320 upon the viability of trypomastigotes.

IVS320 was even more active than the analogs originated from the insertion of 1,2,3-triazole in the 1,4-naphthoquinone structure, where they showed $\mathrm{IC}_{50}$ that ranged from 10 to $17 \mu \mathrm{M}$ [31]. In addition, IVS320 was the most effective among the 2-aminonaftoquinone derivatives in which, despite the increased time of exposure to the parasite, showed $\mathrm{IC}_{50}$ values around $7.5 \mu \mathrm{M}$ [32].

In order to identify potential biological activities of IVS320, reverse virtual screening was performed in more than 9000 targets. The results showed that IVS320 was strongly bound to two targets: Nucleoside hydrolase (PDB ID: 1HP0) [33,34] and pteridine reductase (PDB ID: 3JQB) [35,36], where both are unique to Trypanosomatidae. The high affinity of IVS320 for these proteins might explain the efficient trypanocidal activity reported in this study. Figure 6 shows a possible binding mode for IVS320 with nucleoside hydrolase from T. cruzi.

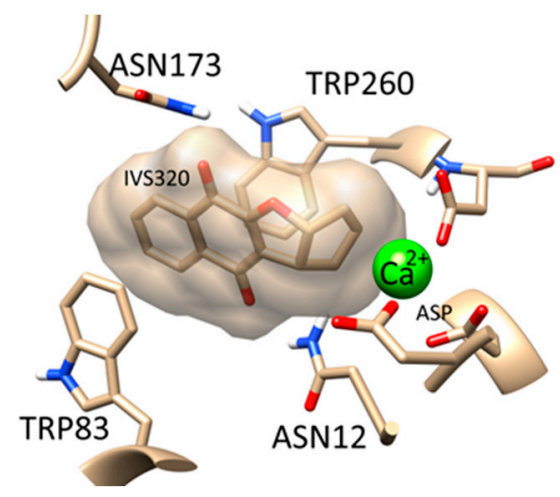

Figure 6. Possible binding mode of IVS320 in the Trypanosomatidae nucleoside hydrolase target.

\section{Materials and Methods}

\subsection{Material}

IVS320 (3a,10b-dihydro-1H-cyclopenta[b]naphtho[2,3-d]furan-5,10-dione) was synthesized by the research group at Universidade Federal Fluminense following their previoulsy reported method [19]. The experiments were conducted using ultrapure water (MILLI Q). Other reagents and chemicals were of analytical grade.

\subsection{Differential Scanning Calorimetry (DSC)}

DSC curves were obtained in a Shimadzu DSC-60 cell, using closed aluminum pans with around $2 \mathrm{mg}$ of IVS320, under dynamic atmosphere of $\mathrm{N}_{2}$ (flow rate of $50 \mathrm{~mL} \cdot \mathrm{min}^{-1}$ ) and heating rate of $10^{\circ} \mathrm{C} \cdot \mathrm{min}^{-1}$ in the temperature range of $25-450{ }^{\circ} \mathrm{C}$. 
Highly pure Zn and In were used to calibrate the DSC equipment, where the experiments were performed at 200 and $500{ }^{\circ} \mathrm{C}$, respectively. Through their melting points $\left(156.65\right.$ and $419.50{ }^{\circ} \mathrm{C}$ for In and $\mathrm{Zn}$, respectively) the areas under the peaks were determined. Once the correction of the calibration temperature was performed, the heat calibration was corrected in which the enthalpy values for In and $\mathrm{Zn}$ were 28.5 and $100.5 \mathrm{~J} \cdot \mathrm{g}^{-1}$, respectively. Further, new experiments were performed to assure that the melting temperature varied in the range of $\pm 0.5^{\circ} \mathrm{C}$ and that the values of melting enthalpy $(\Delta H)$ varied in the range of $\pm 1.0 \mathrm{~J} \cdot \mathrm{g}^{-1}$. Once these parameters were reached, the calibration was accomplished.

\subsection{Termogravimetry \& Differential Thermal Analysis (TG and DTA)}

TG and DTA curves for IVS320 were obtained on a SHIMADZU thermobalance, model TGA 60 (simultaneous TG/DTA), using an alumina pan (samples weighting $8 \pm 0.1 \mathrm{mg}$ ) at a heating rate of $10{ }^{\circ} \mathrm{C} \cdot \mathrm{min}^{-1}$ in the $25-900{ }^{\circ} \mathrm{C}$ temperature range, under dynamic atmosphere of Air and $\mathrm{N}_{2}$ at $50 \mathrm{~mL} \cdot \mathrm{min}^{-1}$.

The TGA 60 equipment was calibrated using In, which was heated up to $200{ }^{\circ} \mathrm{C}$ followed by correction of the calibration temperature. Next, another experiment was run with the purpose of checking whether the melting temperature varied within $\pm 0.5^{\circ} \mathrm{C}$.

In order to identify the thermal events presented as well as the temperatures ( $T_{\text {onset, }}$, and $\left.T_{\text {peak }}\right)$ and energies $\left(\mathrm{J} \cdot \mathrm{g}^{-1}\right)$ involved in these events, thermal curves were analyzed with the aid of the SHIMADZU software TASYS.

\subsection{X-ray Fluorescence}

For the X-ray fluorescence analysis, a X-ray Fluorescence by Dispersion of Energy (XRFDE) spectrometer, model EDX-700 (Shimadzu ${ }^{\circledR}$ ), was used. X-ray data were obtained using a Rhodium tube with voltage from 0 to $40 \mathrm{KeV}$, collected after $250 \mathrm{~s}$. All chemical elements were identified by their $K \alpha$ or $L \alpha$ energies and the quantification was performed based on the relative intensities of cps/uA.

The quantification of the elements found in IVS320 was performed using external high-purity standards at six predetermined concentrations, which were subjected to the same analysis protocol.

\subsection{X-ray Diffraction}

X-ray diffraction analysis were performed using a XRD $6000\left(\right.$ Shimadzu $\left.^{\circledR}\right)$ with $\mathrm{CuK} \alpha$ radiation generated at $40 \mathrm{kV}$ and $30 \mathrm{~mA}, 2.0$ speed $0 / \mathrm{min}, 0.020$ pitch, with scanning from 10 to 600 . Crystallinity of the material was calculated using the following equation:

$$
\text { crystallinity }=\frac{1}{1+K \times \frac{I_{a}}{I_{c r}}}
$$

where the integral intensities of the crystalline and amorphous parts are $\mathrm{I}_{\mathrm{cr}}$ and $\mathrm{I}_{\mathrm{a}}$, respectively, and the ratio of X-ray intensity of the amorphous part, which scatters from a fixed amount of material, to that of its crystalline part is $\mathrm{K}$.

\subsection{Fourrier Transform Infrared (FT-IR)}

The FT-IR spectrum (4000-400 $\mathrm{cm}^{-1}$ ) was obtained on a Prestige-21 FT-IR spectrophotometer $\left(\right.$ Shimadzu $\left.{ }^{\circledR}\right)$ equipped with a selenium crystal. The number of scans was 120 and the resolution was $4 \mathrm{~cm}^{-1}$.

\subsection{Scanning Electron Microscopy (SEM)}

The morphology of IVS320 powder was obtained by SEM. Sample was fixed on stub with double carbon tape and imaged on a Tabletop Microscope TM300 (Hitachi $\left.{ }^{\circledR}\right)$ at a magnification of $500 \times$. 


\subsection{Hygroscopicity}

Hygroscopicity was determined according to the method described by Callahan and co-workers [28] with some modifications. Briefly, $50 \mathrm{mg}$ of IVS320 was subjected to different relative humidity conditions ( $88.8 \%$ and $70.4 \%$ ), which were obtained by using sulfuric acid solution at 4.92 and $8.68 \mathrm{~N}$, respectively, for $3,24,48$ and $72 \mathrm{~h}$.

The hygroscopicity of IVS320 was determined as percentage of water absorbed $(\mathrm{H} \%)$, which was calculated using the following equation:

$$
\mathrm{H} \%=[(\mathrm{Wh}-\mathrm{Wd}) / \mathrm{Wd}] \times 100
$$

where Wh and Wd are the weight of the sample after (humid) and before (dried) submitting IVS320 to a fixed relative humidity environment.

\subsection{Partition Coefficient/Lipophilicity}

Partition coefficient of IVS320 was determined according to the slow-stirring method adapted for poorly soluble drugs [37]. In this experiment, 1-octanol and distilled water were used as the organic and aqueous phases, respectively, where the two phases were subjected to saturation for two days prior to the experiment.

IVS320 was added to the 1-octanol/water system and subjected to slow stirring at room temperature for 5 days. The turbulence between the two phases was controlled to prevent emulsification. IVS320 was quantified at the aqueous and octanolic phases by spectrophotometry in the UV region $(268 \mathrm{~nm})$. The partition coefficient $(\mathrm{P})$ was calculated as the ratio between the concentration of IVS320 in the 1-octanol and water phases, $\mathrm{P}=$ [1-octanol]/[water]. Lipophilicity, denoted as $\log \mathrm{P}$, was measured as the base 10 logarithm of $P$. The experiment was performed in triplicate.

\subsection{Solubility Studies}

The qualitative solubility of IVS320 was determined using solvents with different polarities: water, acetonitrile, methanol, ethanol, dichloromethane, ethyl ether, oleic acid, dipropylene, ortho-phosphoric acid, hexane, chloroform, petroleum ether, glycerin, folic acid, acetic anhydride, acetic acid, and acetone. A fixed amount of IVS320 (1 mg) was added to different volumes of each solvent $(1,10,100$ and $1000 \mathrm{~mL})$ and subjected to vigorous mechanical stirring at $25^{\circ} \mathrm{C}\left( \pm 2{ }^{\circ} \mathrm{C}\right)$ for $12 \mathrm{~h}$. The obtained dispersion was filtered $(0.45 \mu \mathrm{m})$ and the amount of IVS320 dissolved was determined spectrophotometrically at $268 \mathrm{~nm}$. This experiment was performed in triplicate.

\subsection{Parasites}

Tissue culture trypomastigotes ( $Y$ strain) were obtained from the supernatants of 5 to 6-days-old infected LLC-MK2 cells maintained in RPMI-1640 medium supplemented with 10\% FBS (FBS; Cultilab, Campinas, Brazil) and $50 \mu \mathrm{g} / \mathrm{mL}$ gentamycin (Novafarma, Anápolis, Brazil) at $37^{\circ} \mathrm{C}$ in a $5 \%$ humidified $\mathrm{CO}_{2}$ atmosphere.

\subsection{Anti-Parasitic Activity}

Tissue culture trypomastigotes obtained from the supernatants of previously infected LLC-MK2 cells were dispensed into 96-well plates $\left(4 \times 10^{5}\right.$ cell/well) in RPMI medium supplemented with $10 \% \mathrm{FBS}$ and $50 \mu \mathrm{g} / \mathrm{mL}$ of gentamycin in the absence or in the presence of different concentrations $(20-0.15 \mu \mathrm{M})$ of IVS320, in triplicate. Viable parasites were counted in a Neubauer chamber at $24 \mathrm{~h}$ after incubation. The percentage of inhibition was calculated in relation to untreated cultures. To determine the inhibitory concentration of $50 \%\left(\mathrm{IC}_{50}\right)$ for trypomastigote forms of $T$. cruzi, a nonlinear regression on Prism 5.02 GraphPad software was used. Experiments were performed in triplicate and benznidazole (LAFEPE, Recife, Brazil) was used as trypanocidal reference drug. 


\subsection{Inverse Virtual Screening}

Around 9000 targets with known ligands were retrieved from the Protein DataBank [38], preprocessed and used to dock IVS320. AutoDock Vina [39] was used for this process. The most favorable binding energies were analyzed and Trypanosomatidae targets were selected and visualized using UCSF Chimera [40].

\section{Conclusions}

This study provided important information regarding the physicochemical properties of the new chemical entity IVS320, which was found to be insoluble in water and in most organic solvents. Its high degree of crystallinity (99.19\%) may have contributed to such poor solubility. Although the antitumor and antifungal activities of IVS320 have been documented, this study demonstrated that this drug has a potent trypanocidal activity against tissue culture trypomastigotes and therefore has potential as a new anti-trypanosoma drug.

This work opens perspectives for future studies attempting to improve IVS320's physical and chemical characteristics, especially solubility and permeability, through inclusion complexes and solid dispersions. Moreover, the in vivo activity of IVS320 needs to be investigated in order to better elucidate its mechanisms of action and further treatment of other infectious diseases.

Acknowledgments: The authors wish to thank the Coordenação de Aperfeiçoamento de Pessoal de Nível Superior (CAPES) and Conselho Nacional de Desenvolvimento Científico e Tecnológico (CNPQ). The authors thank Vitor Francisco Ferreira for the synthesis of IVS320.

Author Contributions: Elen Diana Dantas, William Nascimento Litaiff Nogueira, Pedro Henrique Antunes de Azevedo performed the experiments. Elen Diana Dantas, Fabia Julliana Jorge de Souza, Pedro Henrique Antunes de Azevedo, Patricia Danielle Oliveira de Almeida performed the literature search and drafted the manuscript. Cláudia Cândida Silva was responsible for X-ray Fluorescence and X-ray Diffraction. Euzébio Guimarães Barbosa was responsible for Inverse virtual screening. Patricia Danielle Oliveira de Almeida and Emerson Silva Lima Carried out the trypanocidal activity. Mariana Filomena do Carmo Cardoso and Vitor Francisco Ferreira Carried out drug synthesis. Cícero Flávio Soares Aragão, Fernando de Carvalho da Silva, Emerson Silva Lima, Vitor Francisco Ferreira, Eduardo Pereira de Azevedo, Ádley Antonini Neves de Lima contributed with the development of concept, data analysis, and writing the manuscript.

Conflicts of Interest: The authors declare no conflict of interest.

\section{References}

1. McKerrow, J.; Doyle, P.; Engel, J.; Podust, L.; Robertson, S.; Ferreira, R.; Saxton, T.; Arkin, M.; Kerr, I.D.; Brinen, L.S.; et al. Two approaches to discovering and developing new drugs for Chagas disease. Mem. Inst. Oswaldo Cruz 2009, 104, 263-269. [CrossRef] [PubMed]

2. Chagas Disease (American Trypanosomiasis)—World Health Organization. Available online: http:/ / www. who.int/chagas/home_more/en/ (accessed on 15 December 2016).

3. Coura, J.R.; Viñas, P.A.; Junqueira, A.C.V. Ecoepidemiology, short history and control of Chagas disease in the endemic countries and the new challenge for non-endemic countries. Mem. Inst. Oswaldo Cruz 2014, 109, 856-862. [CrossRef] [PubMed]

4. Vermelho, A.B.; Capaci, G.R.; Rodrigues, I.A.; Cardoso, V.S.; Mazotto, A.M.; Supuran, C.T. Carbonic anhydrases from Trypanosoma and Leishmania as anti-protozoan drug targets. Bioorg. Med. Chem. 2017, 25, 1543-1555. [CrossRef] [PubMed]

5. Lima, Á.A.; Soares-Sobrinho, J.L.; Silva, J.L.; Corrêa-Júnior, R.A.; Lyra, M.A.; Santos, F.L.; Oliveiran, B.G.; Hernandes, M.Z.; Rolim, L.A.; Rolim-Neto, P.J. The use of solid dispersion systems in hydrophilic carriers to increase benznidazole solubility. J. Pharm. Sci. 2011, 100, 2443-2451. [CrossRef] [PubMed]

6. Pereira, P.C.M.; Navarro, E.C. Challenges and perspectives of Chagas disease: A review. J. Venom. Anim. Toxins Incl. Trop. Dis. 2013, 34. [CrossRef] [PubMed]

7. Freire, C.P.V.; Ferreira, S.B.; Oliveira, N.S.M.; Matsuura, A.B.J.; Gama, I.L.; Silva, F.C.; Souza, M.C.B.V.; Lima, E.S.; Ferreira, V.F. Synthesis and biological evaluation of substituted $\alpha$-and $\beta-2,3$-dihydrofuran naphthoquinones as potent anticandidal agents. MedChem Comm 2010, 1, 229-232. [CrossRef] 
8. Silva, F.C.; Ferreira, V.F. Natural naphthoquinones with great importance in medicinal chemistry. Curr. Org. Synth. 2016, 13, 334-371. [CrossRef]

9. Bhasin, D.; Chettiar, S.N.; Etter, J.P.; Mok, M.; Li, P.K. Anticancer activity and SAR studies of substituted 1, 4-naphthoquinones. Bioorg. Med. Chem. 2013, 21, 4662-4669. [CrossRef] [PubMed]

10. Kadela-Tomanek, M.; Bębenek, E.; Chrobak, E.; Latocha, M.; Boryczka, S. Alkoxy and Enediyne Derivatives Containing 1,4-Benzoquinone Subunits-Synthesis and Antitumor Activity. Molecules 2017, $22,447$. [CrossRef] [PubMed]

11. Sreelatha, T.; Kandhasamy, S.; Dinesh, R.; Shruthy, S.; Shweta, S.; Mukesh, D.; Karunagaran, D.; Balaji, R.; Mathivanan, N.; Perumal, P.T. Synthesis and SAR study of novel anticancer and antimicrobial naphthoquinone amide derivatives. Bioorg. Med. Chem. 2014, 24, 3647-3651. [CrossRef] [PubMed]

12. Janeczko, M.; Demchuk, O.M.; Strzelecka, D.; Kubiński, K.; Masłyk, M. New family of antimicrobial agents derived from 1,4-naphthoquinone. Eur. J. Med. Chem. 2016, 124, 1019-1025. [CrossRef] [PubMed]

13. Pavela, R. Efficacy of naphthoquinones as insecticides against the house fly, Musca domestica L. Ind. Crop. Prod. 2013, 43, 745-750. [CrossRef]

14. Sodero, A.C.R.; Abrahim-Vieira, B.; Torres, P.H.M.; Pascutti, P.G.; Garcia, C.R.; Ferreira, V.F.; Rocha, D.R.; Ferreira, S.B.; Silva, F.P., Jr. Insights into cytochrome bc1 complex binding mode of antimalarial 2-hydroxy-1, 4-naphthoquinones through molecular modelling. Mem. Inst. Oswaldo Cruz 2017, 112, 299-308. [CrossRef] [PubMed]

15. Woo, H.J.; Jun, D.Y.; Lee, J.Y.; Park, H.S.; Woo, M.H.; Park, S.J.; Kim, S.C.; Yang, C.H.; Kim, Y.H. Anti-inflammatory action of 2-carbomethoxy-2,3-epoxy-3-prenyl-1, 4-naphthoquinone (CMEP-NQ) suppresses both the MyD88-dependent and TRIF-dependent pathways of TLR4 signaling in LPS-stimulated RAW264. 7 cells. J. Ethnopharmacol. 2017, 205, 103-115. [CrossRef] [PubMed]

16. Araújo, M.V.; David, C.C.; Neto, J.C.; Oliveira, L.A.; Silva, K.C.; Santos, J.M.; Silva, J.K.S.; Brandão, V.B.C.A.; Silva, T.M.S.; Camara, C.A.; Alexandre-Moreira, M.S. Evaluation on the leishmanicidal activity of 2-N,N'-dialkylamino-1,4-naphthoquinone derivatives. Exp. Parasitol. 2017, 176, 46-51. [CrossRef]

17. Naujorks, A.A.S.; Silva, A.O.; Silva Lopes, R.; Albuquerque, S.; Beatriz, A.; Marques, M.R.; Lima, D.P. Novel naphthoquinone derivatives and evaluation of their trypanocidal and leishmanicidal activities. Org. Biomol. Chem. 2015, 13, 428-437. [CrossRef] [PubMed]

18. Sánchez-Calvo, J.M.; Barbero, G.R.; Guerrero-Vásquez, G.; Durán, A.G.; Macías, M.; Rodríguez-Iglesias, M.A.; Molinillo, J.M.G.; Macías, F.A. Synthesis, antibacterial and antifungal activities of naphthoquinone derivatives: A structure-activity relationship study. Med. Chem. Res. 2016, 6, 1274-1285. [CrossRef]

19. Nair, V.; Treesa, P.M.; Maliakal, D.; Rath, N.P. CAN Mediated oxidative addition of 2-hydroxynaphthoquinone to dienes: A facile synthesis of naphthofurandiones. Tetrahedron 2001, 57, 7705-7710. [CrossRef]

20. Ferreira, M.P.S.B.C.; Cardoso, M.F.C.C.; Silva, F.C.; Ferreira, V.F.; Lima, E.S.; Souza, J.V.B. Antifungal activity of synthetic naphthoquinones against dermatophytes and opportunistic fungi: Preliminary mechanism-of-action tests. Ann. Clin. Microbiol. Antimicrob. 2014, 13, 1-6. [CrossRef] [PubMed]

21. Láng, P.; Kiss, V.; Ambrus, R.; Farkas, G.; Szabó-Révész, P.; Aigner, Z.; Várkonyi, E. Polymorph screening of an active material. J. Pharm. Biomed. Anal. 2013, 84, 177-183. [CrossRef] [PubMed]

22. Freitas-Neto, J.L.; Presmich, G.M.A.; Rolim, L.A.; Alves, L.D.S.; Albuqueque, M.M.; Rolim-Neto, P.J. Caracterização físico-química do potencial agente antineoplásico $\beta$-lapachona. Rev. Ciênc. Farm. Básica Apl. 2013, 33, 545-553.

23. Dinunzio, J.C.; Brough, C.; Miller, D.A.; Williams, R.O.; McGinitya, J.W. Applications of KinetiSol ${ }^{\circledR}$ Dispersing for the production of plasticizer free amorphous solid dispersions. Eur. J. Pharm. Sci. 2010, 40, 179-187. [CrossRef] [PubMed]

24. Bharate, S.S.; Vishwakarma, R.A. Impact of preformulation on drug development. Expert Opin. Drugs Deliv. 2013, 10, 1239-1257. [CrossRef] [PubMed]

25. Newman, A.W.; Reutzel-Edens, S.M.; Zografi, G. Characterization of the "hygroscopic" properties of active pharmaceutical ingredients. J. Pharm. Sci. 2008, 97, 1047-1059. [CrossRef] [PubMed]

26. Murikipudi, V.; Gupta, P.; Sihorkar, V. Efficient throughput method for hygroscopicity classification of active and inactive pharmaceutical ingredients by water vapor sorption analysis. Pharm. Dev. Technol. 2013, 18, 348-358. [CrossRef] [PubMed]

27. Fassihi, A.R.; Persicaner, P.H.R. Solid state interaction of bromazepam with polyvinylpyrrolidone in the presence of moisture. Int. J. Pharm. 1987, 37, 167-170. [CrossRef] 
28. Callahan, J.C.; Cleary, G.W.; Elefant, M.; Kaplan, G.; Kensler, T.; Nash, R.A. Equilibrium moisture content of pharmaceutical excipients. Drug Dev. Ind. Pharm. 1982, 8, 355-369. [CrossRef]

29. Yang, Y.; Engkvist, O.; Llinàs, A.; Chen, H. Beyond size, ionization state, and lipophilicity: Influence of molecular topology on absorption, distribution, metabolism, excretion, and toxicity for druglike compounds. J. Med. Chem. 2012, 55, 3667-3677. [CrossRef] [PubMed]

30. Ferreira, V.F.; Jorqueira, A.; Souza, A.M.; Silva, M.N.; Souza, M.C.; Gouvêa, R.M.; Rodrigues, C.R.; Pinto, A.V.; Castro, H.C.; Santos, D.O.; et al. Trypanocidal agents with low cytotoxicity to mammalian cell line: A comparison of the theoretical and biological features of lapachone derivatives. Bioorg. Med. Chem. 2006, 14, 5459-5466. [CrossRef] [PubMed]

31. Dahan, A.; Miller, J.M.; Hoffman, A.; Amidon, G.E.; Amidon, G.L. The solubility-permeability interplay in using cyclodextrins as pharmaceutical solubilizers: Mechanistic modeling and application to progesterone. J. Pharm. Sci. 2010, 99, 2739-2749. [CrossRef] [PubMed]

32. Silva Júnior, E.N.; Melo, I.M.M.; Diogo, E.B.T.; Costa, V.A.; Souza Filho, J.D.; Valença, W.O.; Camara, C.A.; Oliveira, R.N.; Araujo, A.S.; Emery, F.S.; et al. On the search for potential anti-Trypanosoma cruzi drugs: Synthesis and biological evaluation of 2-hydroxy-3-methylamino and 1,2,3-triazolic naphthoquinoidal compounds obtained by click chemistry reactions. Eur. J. Med. Chem. 2012, 52, 304-312. [CrossRef] [PubMed]

33. Sieveking, I.; Thomas, P.; Estévez, J.C.; Quiñones, N.; Cuéllar, M.A.; Villena, J.; Espinosa-Bustos, C.; Fierro, A.; Tapia, R.A.; Maya, J.D.; et al. 2-Phenylaminonaphthoquinones and related compounds: Synthesis, trypanocidal and cytotoxic activities. Bioorg. Med. Chem. 2014, 22, 4609-4620. [CrossRef] [PubMed]

34. Versées, W.; Decanniere, K.; Van-Holsbeke, E.; Devroede, N.; Steyaert, J. Enzyme-substrate interactions in the purine-specific nucleoside hydrolase from Trypanosoma vivax. J. Biol. Chem. 2002, 277, 15938-15946. [CrossRef] [PubMed]

35. Versées, W.; Decanniere, K.; Pellé, R.; Depoorter, J.; Brosens, E.; Parkin, D.W.; Steyaert, J. Structure and function of a novel purine specific nucleoside hydrolase from Trypanosoma vivax. J. Mol. Biol. 2001, 307, 1363-1379. [CrossRef] [PubMed]

36. Schormann, N.; Pal, B.; Senkovich, O.; Carson, M.; Howard, A.; Smith, C.; Delucas, L.; Chattopadhyay, D. Crystal structure of Trypanosoma cruzi pteridine reductase 2 in complex with a substrate and an inhibitor. J. Struct. Biol. 2005, 152, 64-75. [CrossRef] [PubMed]

37. Organisation for Economic Co-operation and Development (OECD). Test No. 123: Partition Coefficient (1-Octanol/Water): Slow-Stirring Method, OECD Guidelines for the Testing of Chemicals; OECD Publishing: Paris, France, 2006; Section 1. Available online: http:/ / www.oecd-ilibrary.org/environment/test-no-123-partitioncoefficient-1-octanol-water-slow-stirring-method_9789264015845-en (accessed on 5 November 2015). [CrossRef]

38. Berman, H.M.; Westbrook, J.; Feng, Z.; Gilliland, G.; Bhat, T.N.; Weissig, H.; Shindyalov, I.N.; Bourne, P.E. The Protein Data Bank. Nucleic Acids Res. 2000, 28, 235-242. [CrossRef] [PubMed]

39. Trott, O.; Olson, A.J. AutoDock Vina: Improving the speed and accuracy of docking with a new scoring function, efficient optimization and multithreading. J. Comput. Chem. 2010, 31, 455-461. [CrossRef] [PubMed]

40. Pettersen, E.F.; Goddard, T.D.; Huang, C.C.; Couch, G.S.; Greenblatt, D.M.; Meng, E.C.; Ferrin, T.E.J. UCSF Chimera-A visualization system for exploratory research and analysis. J. Comput. Chem. 2004, 25, 1605-1612. [CrossRef] [PubMed]

Sample Availability: Samples of the compound IVS320 are available from the authors. 